\title{
BMJ open Occupation and the risk of bothersome tinnitus: results from a prospective cohort study (HUNT)
}

\author{
Bo Engdahl, ${ }^{1}$ Norun Hjertager Krog, ${ }^{1}$ Ellen Kvestad, ${ }^{1}$ \\ Howard J Hoffman, ${ }^{2}$ Kristian Tambs ${ }^{1,3}$
}

To cite: Engdahl B, Krog NH, Kvestad $\mathrm{E}$, et al. Occupation and the risk of bothersome tinnitus: results from a prospective cohort study (HUNT). BMJ Open 2012;2: e000512. doi:10.1136/ bmjopen-2011-000512

- Prepublication history for this paper is available online. To view these files please visit the journal online (http:// bmjopen.bmj.com).

Received 21 October 2011 Accepted 28 November 2011

This final article is available for use under the terms of the Creative Commons Attribution Non-Commercial 2.0 Licence; see http://bmjopen.bmj.com

\footnotetext{
${ }^{1}$ Norwegian Institute of Public Health, Division of Mental Health, Oslo, Norway ${ }^{2}$ Epidemiology and Statistics Program, National Institute on Deafness and Other Communication Disorders (NIDCD), National Institutes of Health (NIH), Bethesda, Maryland, USA

${ }^{3}$ Departments of Psychiatry and Human Genetics, Virginia Commonwealth University, Richmond, Virginia, USA
}

Correspondence to Dr Bo Engdahl; bo.engdahl@fhi.no

\section{ABSTRACT}

Objectives: Estimates of occupation-specific tinnitus prevalence may help identify high-risk occupations where interventions are warranted. The authors studied the effect of occupation on prevalence of bothersome tinnitus and estimated the attributable fraction due to occupation. The authors also studied how much of the effect remained after adjusting for noise exposure, education income, hearing thresholds and other risk factors.

Design: A prospective cohort study.

Setting: A health survey of the Nord-Trøndelag county of Norway.

Participants: A sample of the general adult population $(n=49$ 948).

Primary outcome measure: The primary outcome measure is bothersome tinnitus.

Results: Occupation had a marked effect on tinnitus prevalence. The effect of occupation on tinnitus was reduced in men by controlling for self-reported occupational noise exposure and in women by controlling for education and income. Adding hearing loss as a predictor increased the effect of occupation somewhat. In men, age-adjusted prevalence ratios of tinnitus ranged from 1.5 (workshop mechanics) to 2.1 (crane and hoist operators) in the 10 occupations with highest tinnitus prevalence. In women, the most important contribution to the tinnitus prevalence was from the large group of occupationally inactive persons, with a prevalence ratio of 1.5.

Conclusion: This study found a moderate association between occupation and bothersome tinnitus.

\section{INTRODUCTION}

Tinnitus, or the perception of sound without an external acoustic stimulus, is a common health complaint in the adult population. In addition to general irritation and annoyance with the sound, tinnitus can cause difficulties with sleep and concentration, reduced speech intelligibility and various psychosomatic, emotional and interpersonal problems. ${ }^{1}$ The prevalence of chronic tinnitus in the adult population is estimated at $8 \%-$ $15 \%$, depending on the definition. ${ }^{2}{ }^{3}$ It is

\section{ARTICLE SUMMARY}

\section{Article focus}

- We studied the effect of occupation on prevalence of bothersome tinnitus and estimated the attributable fraction due to occupation.

- We also studied if the effect remained after adjustment for noise exposure, education and income, other risk factors and hearing threshold.

Key messages

- There are very few epidemiological studies quantifying work-related tinnitus risk, and our large and representative sample gives precise estimates of occupational risk.

- This study shows moderate effects of occupation on bothersome tinnitus and presents prevalence estimates of 122 different occupations in 49948 subjects.

- Noisy occupations were associated with an increased risk of bothersome tinnitus in men, but in women, occupations with the highest risk for tinnitus were not typically noisy ones, and the attributable fraction was determined mainly by the group of occupationally inactive.

Strengths and limitations of this study

- The major advantages of the present study are the prospective design and that the study population is representative of the general working population.

- The occupations are not classified by risk factors for tinnitus, but according to the tasks and duties undertaken in the job. Heterogeneity regarding exposure within occupational categories implies that occupation, as an explanatory variable, does not capture all effects of occupational exposures on tinnitus.

higher in men and increases with age up to a certain point, after which it declines. ${ }^{3-5}$

Tinnitus frequently occurs together with permanent hearing loss, ${ }^{6} 7$ suggesting that tinnitus may be associated with cochlear damage. Tinnitus shares many of the same risk factors as hearing loss, including occupational noise, work-related diseases, exposure to toxins, non-occupational noise 
exposure, drugs or medications, otological diseases, dizziness, head injury and socioeconomic and general health status. ${ }^{4-11}$

However, tinnitus is not always secondary to hearing loss and may occur in individuals with normal hearing. Some have suggested that tinnitus is an early sign of hearing loss, in particular noise-induced hearing loss, ${ }^{12}$ although there are studies opposing this hypothesis. ${ }^{13}$ Central nervous system mechanisms are believed to play an important role in the pathology of tinnitus. ${ }^{14}$ Therefore, risk factors related to neural plasticity and sensitisation may be of importance. Stress seems to play a role: patients often report worsening of tinnitus with stress. Workers perceiving high job stress have an increased risk of tinnitus, ${ }^{9}{ }^{15}$ and tinnitus may be induced by stressful life events and trauma. ${ }^{16}$ Work-related stress such as low degree of control, conflicting work demands, conflict between work and family life and lack of support from superiors may therefore be risk factors for tinnitus. Tinnitus has been associated with mental health and well-being, ${ }^{17}$ factors that might themselves be work related, thus mediating the association between occupation and tinnitus. The direction of influence between tinnitus and many of these factors is, however, unclear, and there may even be bidirectional relationships. ${ }^{18}$

Although tinnitus has been associated with a few occupational risk factors such as noise exposure,, 58911 there are very few studies quantifying occupationalspecific tinnitus risk. ${ }^{4}$ Epidemiological studies of workrelated tinnitus are needed in order to identify high-risk occupations with specific types of harmful exposure so that protective measures can be implemented.

Previous analyses of data from the Nord-Trøndelag Hearing Loss Study (NTHLS) showed effects of selfreported occupational and impulse noise exposure on tinnitus. ${ }^{4}$ Analyses also revealed effects of education, income, general health status, recurrent ear infections, head injury and cigarette smoking. Frequent exposure to loud music and having played in a band were, in contrast, more frequent among subjects without tinnitus. Detailed information on occupation type was not included in the previous analyses. However, information from the nationwide occupation register has recently been used to study the effect of occupation-specific hearing loss. ${ }^{19}$

The primary aim of the present study was to determine the effect of occupation on bothersome tinnitus. Second, we estimated the fraction of tinnitus that can be attributed to occupation-associated risks. We also wanted to examine the extent to which differences in tinnitus between the various occupations remained after adjustment for self-reported occupational noise exposure, non-occupational noise exposure, other risk factors, education, income and hearing loss.

\section{MATERIALS AND METHODS}

Study population

The NTHLS is part of the Nord-Trøndelag Health Study (HUNT-2). The entire adult population of
Nord-Trøndelag county in Norway was invited to participate in HUNT-2, which was conducted from January 1996 to February 1998. Screening included several types of examinations and two questionnaires (HUNT-2 Q1 and Q2). Seventeen of the 24 municipalities were offered and accepted hearing examination, consisting of pure-tone audiometry and the completion of two questionnaires (Hearing Q1 and Q2), as part of the screening program.

The subjects ranged in age from 20 to 101 years (median 48.0 years; mean (SD) 50.2 (17.0) years). The participation rate for all municipalities was $69 \%$ except one (Levanger), 65\% among male subjects and $73 \%$ among female subjects. The corresponding rates for Levanger (where the HUNT-2 participants had to be re-invited to have their hearing examined) were $42 \%$, $39 \%$ and $45 \%$ overall and for male subjects and female subjects, respectively. The participation rates varied with age, from about $40 \%$ for subjects younger than 30 years or older than 80 years to $82 \%$ for subjects from 60 to 69 years. The low participation rate among young people is likely due in part to the absence of students and young adults serving their (compulsory) military service who, while formally keeping their childhood home address, had moved to other parts of the country.

A total of 51574 persons arrived for their hearing examination and provided written informed consent. Participants completed a questionnaire (Hearing Q1) on hearing-related information at the examination site. Audiometric data were missing for 774 persons (1.5\%). Questionnaire data were missing or incomplete for 815 persons $(1.6 \%)$. The sample is described in greater detail elsewhere. ${ }^{20}$

Information on occupation, education and income was obtained for all, but 37 subjects from the population register information from Statistics Norway. In total, the sample consisted of 49948 subjects with complete data.

\section{Measures}

The Hearing Q1 included questions about bothersome tinnitus. Tinnitus was here defined by a 'yes' response to the single general question: 'Are you bothered by ringing in the ears?' Missing values and a 'no' response were considered equivalent to 'not bothered'. The Hearing Q2 included a slightly differently phrased question about the degree to which the respondent is bothered by tinnitus (response categories: not bothered, a little bothered and strongly bothered). In the present study, the question and data from Q1 were used. Previous analysis has shown a test-retest polychoric correlation for 27792 persons tested twice on both Q1 and $\mathrm{Q} 2$, with the majority of time lags ranging from 3 to 6 months, of 0.65 (95\% CI 0.63 to 0.66 ) indicating relatively high reliability for our tinnitus measure. ${ }^{21}$

Data on occupation were obtained using census records from 1970, 1980 and 1990. The most recent occupation information was used. For example, if a subject was not working in 1990, his or her occupation 
status from 1980 was used. About $22 \%$ of the population (14\% of male subjects and $30 \%$ of female subjects) had no registered occupation (ie, were occupationally inactive) during all the census registration years. Occupation was coded according to the Nordic Classification of Occupations $^{22}$ using a three-digit code. The digits represent the major class ('felt'), the sector ('område') and the occupation group. The codes consist of 13, 86 and 412 groups, respectively. ${ }^{23}$ For supplementary analyses, the group of occupationally inactive was further distinguished into subclasses based on questions on working situation in the HUNT-2 Q1. The subgroups were (1) full-time household workers, (2) military service or student, (3) unemployed and (4) receiving social security or disability pension. These latter groups were not mutually exclusive, so that individuals could belong to more than one of these groups.

Education data were available for 1980, 1985, 1990, 1995 and 1998. We used the most recent education information. Education was classified into nine levels, from elementary school to tertiary studies leading to advanced professional degrees.

Income data from 1980, 1985, 1990, 1995 and 1998 were calculated as the mean income over the years available, corrected for an increase in the general population income during the period 1980-1998.

Self-reported noise exposure and other risk factors for hearing loss were obtained from the Hearing Q1. Occupational noise exposure was measured by questionnaire items on the duration of exposure to loud noise at work in general (scored $0-3$ ) and from specific noise sources: staple gun/hammering, metal hammering/riveting, circular saw/machine planing, chain saw operation, tractor/construction machines, sledgehammer operation, blasting, machine room noise and other factory noise (scored as 'yes' or 'no'). Non-occupational risk factors were measured by questionnaire items about impulse noise (ie, explosions, shootings); playing in a band or going to discotheques, rock concerts or similar loud events; recurrent ear infections (in childhood or later); hospitalisation (ever) for a head injury (scored as 'no', 'perhaps or I don't know' and 'yes') and smoking cigarettes daily (scored as 'no', 'yes, for 0 to $<5$ years', 'yes, for $\geq 5$ to $<15$ years', 'yes, for $\geq 15$ years'). The items on the questionnaire are described in detail elsewhere. ${ }^{4} 24$

Air conduction hearing thresholds were obtained by pure-tone audiometry as described in an earlier publication. ${ }^{20}$ The hearing scores were computed as puretone average on the worse ear for three independent mean values: (1) low-frequency hearing level (250 and $500 \mathrm{~Hz}$ ), (2) medium-frequency hearing level (1000 and $2000 \mathrm{~Hz}$ ) and (3) high-frequency hearing level (3000, 4000, 6000 and $8000 \mathrm{~Hz}$ ).

\section{Statistical methods}

The effects of occupation on the prevalence of tinnitus were estimated using a log-binomial model with occupation group and age in 5-year groups as fixed factors. The analyses were stratified by sex and age groups $(20-44,45-64$ and $\geq 65$ years). The model, a generalised linear model in which the link function is the logarithm of the proportion under study and the distribution of the error is binomial, was estimated by maximum likelihood. The occupation groups 060-069 were aggregated into one occupation group 06 'pedagogical work' and used as a reference with a sufficient number of subjects for estimating prevalence ratios (PRs). Occupations with fewer than 40 subjects were collapsed into one group. Direct estimates of PRs by logbinomial regression have some advantages over ORs estimated with logistic regression analysis, ${ }^{25}$ and the high prevalence of tinnitus in our sample makes PRs easier to interpret.

Overall model fit was determined by the residual deviance, the lack of fit that remains after modelling with $m$ predictors, as well as the McFadden pseudo $R^{2}$ defined as:

$$
R_{l}^{2}=1-\frac{\ln \left(L_{m}\right)}{\ln \left(L_{0}\right)}
$$

where $L_{m}$ is the likelihood function of the model containing $m$ predictors and $L_{0}$ is the likelihood function of the model containing only the intercept. As $R_{l}^{2}$ does not reach 1 , a rule of thumb is that the model has an excellent fit with $R_{l}^{2}$ being between 0.2 and $0.4 .^{26}$

The overall effect of occupation in the model was estimated by the partial $R_{l}^{2}$ (the difference in $R_{l}^{2}$ values between a model with and without occupation). Changes in the overall effect of occupation by controlling for hearing loss, self-reported noise exposure, other risk factors, education and income were measured by changes in partial $R_{l}^{2}$ after subsequently entering additional control variables in the model.

In order to estimate the portion of tinnitus cases in the population that can be attributed to an occupation, the occupation-specific adjusted attributable fraction (AF) was calculated by the following formula: ${ }^{27}$

$$
\operatorname{pd}_{i} \frac{\mathrm{PR}_{i}-1}{\mathrm{PR}_{i}},
$$

where $\mathrm{PR}_{i}$ is the adjusted prevalence ratio for the $i$ th occupation relative to occupation group 063 and $\mathrm{pd}_{i}$ represents the proportion of cases in the $i$ th occupation to the total population. The sum of the occupationspecific adjusted $\mathrm{AF}$ is thus:

$$
1-\sum_{i=0}^{k} \frac{\mathrm{pd}_{i}}{\mathrm{PR}_{i}}
$$

where $k$ is the total number of occupations.

The 95\% CIs of the occupation-specific AF where estimated by non-linear bootstrapping with the percentile method and 1000 replications. All statistical analyses 
Table 1 Tinnitus prevalence

\begin{tabular}{|c|c|c|c|c|}
\hline \multirow[b]{2}{*}{ Age group } & \multicolumn{2}{|l|}{ Men } & \multicolumn{2}{|l|}{ Women } \\
\hline & Sample size & $\begin{array}{l}\text { Tinnitus } \\
\text { prevalence (\%) }\end{array}$ & Sample size & $\begin{array}{l}\text { Tinnitus } \\
\text { prevalence (\%) }\end{array}$ \\
\hline All & 23374 & 16.4 & 26574 & 12.1 \\
\hline 20-44 years & 9359 & 10.6 & 10920 & 8.4 \\
\hline $45-64$ years & 8618 & 18.5 & 9246 & 12.0 \\
\hline$>64$ years & 5397 & 23.0 & 6408 & 18.7 \\
\hline
\end{tabular}

were performed using the computer program $\mathrm{R}$, V.2.11.1.

\section{RESULTS}

The tinnitus prevalence is higher in men and increases by age (table 1 ).

The goodness of fit (viz., pseudo $R^{2}$ ) for models of tinnitus prevalence by age, occupation, self-reported noise exposure, other risk factors, education, income and hearing loss, entered step- and block-wise, are shown in tables 2 and 3 for men and women, respectively. Occupation contributed significantly to the prediction of tinnitus after adjusting for age in all age groups and for both sexes. Differences in pseudo $R^{2}$ values, $\Delta R_{l}^{2}$, for each model showing specifically the additional effect of occupation compared with the same model without occupation, ranged from $0.9 \%$ to $2.5 \%$. The effects of occupation as observed by $\Delta R_{l}^{2}$ were higher in men than in women and highest in men older than 64 years. In all strata, the best-fit model was obtained with the complete set of predictors, with a significant increase in pseudo $R^{2}$ value for each step.

Controlling for self-reported occupational noise exposure reduced the effect of occupation only in men aged 45 years or older. The effect of occupation was still statistically significant. Additional control for leisurerelated noise, recurrent ear infections, head injuries and smoking had little influence on the effect of occupation at all; this was also true when controlling for education and income. Controlling for hearing loss, however, increased the effect of occupation somewhat.

In women, the effect of occupation was not reduced by controlling for self-reported occupational noise exposure or by controlling for leisure-related noise, recurrent ear infections, head injuries and smoking. However, controlling for education and income considerably reduced the estimated effect of occupation, so that the effect was no longer statistically significant.

Tables 4 and 5 report the predicted age-adjusted prevalence estimates for tinnitus according to various occupational groups. The tables also show the AFs-the fraction of tinnitus cases in the population attributed to an occupation. The aggregated occupational group 'pedagogical work' was specified as a reference group. For men, the occupations with the highest PRs were crane and hoist operators and miners, with PRs of 2.1 and 1.9, respectively. For women, laboratory assistants had the highest PR, 1.9. The large group of subjects with no reported occupation had the highest AFs both in men and in women, although their PR was moderate, 1.2 and 1.5, respectively. The sum of all occupation-specific age-adjusted AFs was estimated to be $13.3 \%$ (95\% CI $9.1 \%$ to $17.0 \%$ ) and $21.4 \%$ (95\% CI $13.9 \%$ to $24.9 \%)$ in men and women, respectively. In women, the overall AF was to a great extent determined by the contribution from the group not reporting an occupation.

In order to further investigate the nature of tinnitus prevalence in the group of occupationally inactive women, we restricted our sample to subjects younger than 65 years $(\mathrm{N}=5850)$. Significant effects after adjustment for age were estimated for receiving social security or disability pension (PR 2.0; 95\% CI 1.6 to $2.5, \mathrm{~N}=567$ ), for being unemployed (PR 1.6; 95\% CI 1.2 to 2.0, $\mathrm{N}=503$ ) and for being full-time household workers (PR $1.2 ; 95 \%$ CI 1.0 to $1.5, \mathrm{~N}=1713$ ). There was no effect of being in the military service or a student (PR 0.9; 95\% CI 0.7 to $1.1, \mathrm{~N}=936)$. The effect of receiving social security or disability pension was slightly reduced by controlling for noise exposure and other risk factors (PR 1.7; 95\% CI 1.4 to 2.1) and further reduced by controlling for education and income (PR 1.4; 95\% CI 1.2 to 1.8). Controlling for hearing loss resulted in a negligible additional change (PR 1.3; 95\% CI 1.1 to 1.6$)$.

\section{DISCUSSION}

Our results showed that occupation has moderate but significant effects on the prevalence of bothersome tinnitus. The effect of occupation on tinnitus prevalence was smaller in women than in men, but the gender difference was not as marked as the previously reported effect of occupation on hearing loss in this sample. ${ }^{19}$ Controlling for self-reported occupational noise exposure reduced the occupation effect in men but had no effect in women; this is likely a confirmation of previous reports that women are in general exposed to less occupational noise. However, additional control for education and income only affected the occupation effect in women.

Several occupations recognised to be associated with loud noise exposure were associated with an increased risk of tinnitus in men and contributed to the overall AF of tinnitus, that is, the fraction of tinnitus cases due to occupation. This is in agreement with previous findings 

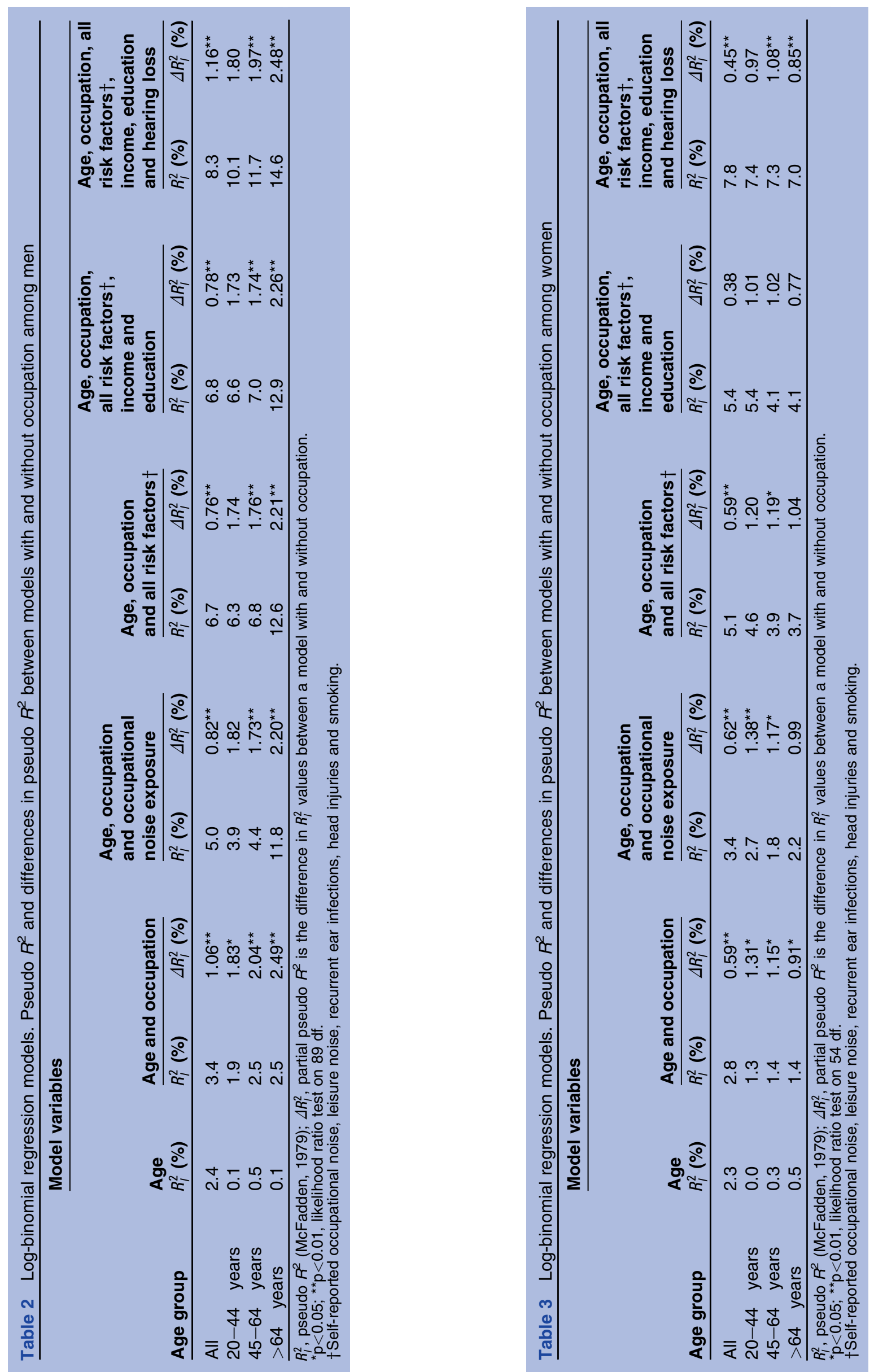
Table 4 Predicted age-adjusted PR and AFs of tinnitus among men*

\begin{tabular}{|c|c|c|c|c|}
\hline \multicolumn{2}{|c|}{ Nordic Classification of Occupational Codes } & \multirow{2}{*}{$\frac{\text { PR }(95 \% \text { Cl) }}{2.1(1.4 \text { to } 3.1)}$} & \multirow{2}{*}{$\frac{\mathrm{AF}(\%) \dagger(95 \% \mathrm{Cl})}{0.23(0.05 \text { to } 0.42)}$} & \multirow{2}{*}{$\begin{array}{c}\begin{array}{l}\text { Sample size } \\
\text { (23 374) }\end{array} \\
53\end{array}$} \\
\hline 872 & Crane and hoist operators, etc & & & \\
\hline 501 & $\begin{array}{l}\text { Miners (in underground mines, quarrymen, } \\
\text { shot firers) }\end{array}$ & 1.9 (1.5 to 2.5$)$ & 0.69 (0.36 to 1.03$)$ & 171 \\
\hline 754 & Sheet-metal workers & 1.8 (1.2 to 2.8$)$ & $0.19(0.01$ to 0.38$)$ & 68 \\
\hline 871 & Stationary engine operators & 1.8 (1.1 to 2.8$)$ & $0.15(-0.01$ to 0.33$)$ & 40 \\
\hline 827 & Dairy workers & 1.7 (1.2 to 2.3$)$ & $0.35(0.11$ to 0.61$)$ & 125 \\
\hline A30 & Military (senior officers) & 1.7 (1.1 to 2.5$)$ & 0.19 (0.01 to 0.39$)$ & 58 \\
\hline 881 & Longshoremen and vehicle loaders & 1.7 (1.1 to 2.6$)$ & $0.17(-0.01$ to 0.37$)$ & 64 \\
\hline 912 & Cooks & 1.7 (1.0 to 2.9$)$ & $0.12(-0.02$ to 0.28$)$ & 55 \\
\hline 909 & $\begin{array}{l}\text { Others in } 90 \text { public safety and } \\
\text { protection work }\end{array}$ & $1.6(1.0$ to 2.7$)$ & $0.11(-0.02$ to 0.26$)$ & 44 \\
\hline 751 & Workshop mechanics & 1.5 (1.1 to 2.0$)$ & $0.33(0.04$ to 0.64$)$ & 183 \\
\hline 757 & Metal plate and steel structural workers & 1.5 (1.1 to 2.0$)$ & $0.32(0.04$ to 0.62$)$ & 174 \\
\hline 77 & Wood work & 1.5 (1.0 to 2.5$)$ & $0.12(-0.04$ to 0.29$)$ & 46 \\
\hline 821 & Millers & 1.5 (0.9 to 2.5$)$ & $0.12(-0.04$ to 0.30$)$ & 51 \\
\hline 331 & Salesmen operating from an office & 1.4 (1.0 to 1.9$)$ & $0.30(-0.02$ to 0.58$)$ & 182 \\
\hline 836 & Papermakers & $1.4(1.0$ to 2.0$)$ & $0.21(-0.01$ to 0.44$)$ & 124 \\
\hline 875 & Material-handling equipment operators & $1.4(0.9$ to 2.1$)$ & $0.15(-0.04$ to 0.36$)$ & 96 \\
\hline $0 \times 6$ & Personnel specialists & 1.4 (0.8 to 2.3$)$ & $0.08(-0.06$ to 0.24$)$ & 50 \\
\hline 876 & Oilers and greasers, etc & $1.4(0.8$ to 2.5$)$ & $0.06(-0.07$ to 0.22$)$ & 57 \\
\hline 753 & Machine and motor repairmen & $1.3(1.0$ to 1.5$)$ & $0.71(0.08$ to 1.31$)$ & 695 \\
\hline 761 & Electricians and electrical fitters & $1.3(1.0$ to 1.6$)$ & $0.39(-0.08$ to 0.83$)$ & 410 \\
\hline 772 & Sawmill and planing mill workers & $1.3(1.0$ to 1.6$)$ & $0.36(-0.06$ to 0.72$)$ & 282 \\
\hline 756 & Welders and flame cutters & $1.3(1.0$ to 1.7$)$ & $0.27(-0.07$ to 0.63$)$ & 256 \\
\hline A10 & Military (corporals and privates) & 1.3 (0.9 to 1.9$)$ & $0.21(-0.07$ to 0.51$)$ & 247 \\
\hline 755 & Plumbers and pipe fitters & 1.3 (0.9 to 1.8$)$ & $0.20(-0.10$ to 0.47$)$ & 177 \\
\hline 75 & Iron and metal ware work & 1.3 (0.9 to 1.9$)$ & $0.14(-0.07$ to 0.36$)$ & 106 \\
\hline 7 & Manufacturing and construction work & 1.3 (0.9 to 2.0$)$ & $0.13(-0.06$ to 0.33$)$ & 86 \\
\hline 769 & Others in 76 electrical work & $1.3(0.9$ to 2.1$)$ & $0.11(-0.08$ to 0.30$)$ & 82 \\
\hline 765 & Linemen and cable jointers & $1.3(0.8$ to 1.9$)$ & $0.10(-0.10$ to 0.31$)$ & 87 \\
\hline 759 & Others in 75 iron and metal ware work & $1.3(0.7$ to 2.2$)$ & $0.06(-0.08$ to 0.22$)$ & 56 \\
\hline $\mathrm{X}$ & Occupation not reported & $1.2(1.0$ to 1.5$)$ & $1.88(0.16$ to 3.33$)$ & 3216 \\
\hline 111 & Directors, managers and working proprietors & $1.2(1.0$ to 1.5$)$ & $0.46(-0.10$ to 0.98$)$ & 469 \\
\hline 003 & $\begin{array}{l}\text { Other engineers, engineer technicians, } \\
\text { industrial designers }\end{array}$ & $1.2(1.0$ to 1.6$)$ & $0.43(-0.07$ to 0.91$)$ & 459 \\
\hline 874 & $\begin{array}{l}\text { Operators of earth-moving and construction } \\
\text { machinery }\end{array}$ & $1.2(1.0$ to 1.6$)$ & $0.36(-0.09$ to 0.76$)$ & 383 \\
\hline 826 & Butchers, sausage makers, etc & $1.2(0.9$ to 1.8$)$ & $0.15(-0.10$ to 0.42$)$ & 157 \\
\hline 299 & Others in 29 other clerical work & $1.2(0.9$ to 1.7$)$ & $0.14(-0.11$ to 0.36$)$ & 149 \\
\hline 853 & Plastic product makers & $1.2(0.8$ to 1.7$)$ & $0.13(-0.13$ to 0.40$)$ & 163 \\
\hline 002 & Chief engineers & $1.2(0.8$ to 1.7$)$ & $0.11(-0.16$ to 0.35$)$ & 153 \\
\hline 781 & Building and furniture painters & $1.2(0.8$ to 1.7$)$ & $0.10(-0.14$ to 0.37$)$ & 146 \\
\hline 105 & $\begin{array}{l}\text { Senior administrators and executive officials, } \\
\text { municipal administration }\end{array}$ & $1.2(0.8$ to 1.7$)$ & $0.08(-0.12$ to 0.30$)$ & 99 \\
\hline 113 & Administration secretaries & $1.2(0.8$ to 2.0$)$ & $0.07(-0.08$ to 0.23$)$ & 57 \\
\hline 834 & Mechanical pulp workers & $1.2(0.7$ to 2.0$)$ & $0.06(-0.09$ to 0.23$)$ & 57 \\
\hline 106 & $\begin{array}{l}\text { Other administrators and executive officials, } \\
\text { municipal administration }\end{array}$ & $1.2(0.7$ to 2.1$)$ & $0.05(-0.09$ to 0.22$)$ & 54 \\
\hline$Y \ddagger$ & Occupations with $<40$ subjects & 1.1 (1.0 to 1.3$)$ & $1.48(-0.31$ to 3.04$)$ & 2519 \\
\hline 774 & Construction carpenters and workers & 1.1 (0.9 to 1.4$)$ & $0.53(-0.28$ to 1.28$)$ & 911 \\
\hline 882 & Warehouse workers & $1.1(0.9$ to 1.5$)$ & $0.16(-0.22$ to 0.53$)$ & 290 \\
\hline 441 & Forestry workers and loggers & 1.1 (0.8 to 1.5$)$ & $0.12(-0.24$ to 0.49$)$ & 276 \\
\hline 641 & Bus drivers & 1.1 (0.8 to 1.7$)$ & $0.08(-0.15$ to 0.32$)$ & 133 \\
\hline 302 & Working proprietors, retail trade & $1.1(0.8$ to 1.6$)$ & $0.06(-0.19$ to 0.32$)$ & 131 \\
\hline $0 \times 2$ & Social workers & $1.1(0.7$ to 1.8$)$ & $0.05(-0.13$ to 0.25$)$ & 92 \\
\hline 822 & Bakers and pastry cooks & 1.1 (0.7 to 1.9$)$ & $0.05(-0.12$ to 0.22$)$ & 78 \\
\hline 612 & Able and ordinary seamen & $1.1(0.6$ to 2.1$)$ & $0.03(-0.11$ to 0.17$)$ & 49 \\
\hline
\end{tabular}


Table 4 Continued

\begin{tabular}{|c|c|c|c|c|}
\hline \multicolumn{2}{|c|}{ Nordic Classification of Occupational Codes } & \multirow{2}{*}{$\frac{\text { PR }(95 \% \text { Cl) }}{1.1(0.6 \text { to } 1.9)}$} & \multirow{2}{*}{$\frac{\mathrm{AF}(\%) \dagger(95 \% \mathrm{CI})}{0.02(-0.13 \text { to } 0.18)}$} & \multirow{2}{*}{$\begin{array}{c}\begin{array}{l}\text { Sample size } \\
(23374)\end{array} \\
61\end{array}$} \\
\hline 119 & $\begin{array}{l}\text { Others in } 11 \text {, administration of private } \\
\text { enterprises and organisations. }\end{array}$ & & & \\
\hline 404 & Managers and supervisors (farms) & $1.1(0.6$ to 1.8$)$ & $0.02(-0.14$ to 0.20$)$ & 84 \\
\hline 031 & Other physicians & $1.1(0.6$ to 2.0$)$ & $0.01(-0.12$ to 0.15$)$ & 49 \\
\hline 793 & Cement finishers, excavators, etc & $1.0(0.8$ to 1.3$)$ & $0.04(-0.48$ to 0.58$)$ & 509 \\
\hline 104 & $\begin{array}{l}\text { Other administration governmental } \\
\text { servants-local state administration }\end{array}$ & $1.0(0.6$ to 1.7$)$ & $0.01(-0.15$ to 0.20$)$ & 80 \\
\hline $0 \times 1$ & Auditors & $1.0(0.6$ to 1.8$)$ & $0.01(-0.14$ to 0.17$)$ & 64 \\
\hline 06 & Pedagogical work & 1.0 (ref) & 0.00 (ref) & 1095 \\
\hline 764 & $\begin{array}{l}\text { Installers, fitters, repairmen (radio, TV, } \\
\text { phone, telegraph) }\end{array}$ & $1.0(0.6$ to 1.6$)$ & $0.00(-0.20$ to 0.21$)$ & 123 \\
\hline $0 \times 9$ & $\begin{array}{l}\text { Others in technical, physical science, } \\
\text { humanistic, artistic work }\end{array}$ & $1.0(0.5$ to 2.1$)$ & $-0.01(-0.12$ to 0.14$)$ & 48 \\
\hline 311 & Salesmen of insurance & $1.0(0.5$ to 1.9$)$ & $-0.01(-0.13$ to 0.12$)$ & 45 \\
\hline 911 & $\begin{array}{l}\text { Housekeepers, etc (not private or public } \\
\text { service) }\end{array}$ & $1.0(0.5$ to 1.8$)$ & $-0.01(-0.14$ to 0.13$)$ & 51 \\
\hline 931 & Janitors, vergers, etc & $1.0(0.7$ to 1.2$)$ & $-0.07(-0.49$ to 0.32$)$ & 333 \\
\hline 644 & Lorry and van drivers & 1.0 (0.8 to 1.2$)$ & $-0.10(-0.75$ to 0.55$)$ & 782 \\
\hline 024 & Silviculturists and forestry consultants & 0.9 (0.5 to 1.7$)$ & $-0.02(-0.16$ to 0.12$)$ & 61 \\
\hline 681 & Postmen & 0.9 (0.5 to 1.6$)$ & $-0.03(-0.18$ to 0.14$)$ & 74 \\
\hline 76 & Electrical work & 0.9 (0.4 to 1.8$)$ & $-0.03(-0.14$ to 0.10$)$ & 48 \\
\hline 671 & Local postmasters, postal assistance & $0.9(0.6$ to 1.5$)$ & $-0.03(-0.22$ to 0.17$)$ & 117 \\
\hline A20 & Non-commissioned officers and subalterns & 0.9 (0.6 to 1.4$)$ & $-0.04(-0.30$ to 0.22$)$ & 164 \\
\hline 643 & Taxi drivers & 0.9 (0.5 to 1.5$)$ & $-0.04(-0.19$ to 0.11$)$ & 70 \\
\hline 791 & Masons, bricklayers and plasterers & $0.9(0.5$ to 1.4$)$ & $-0.05(-0.24$ to 0.14$)$ & 101 \\
\hline 333 & Shop assistants & 0.9 (0.6 to 1.2$)$ & $-0.17(-0.53$ to 0.22$)$ & 373 \\
\hline 663 & Railway supervisors & $0.8(0.4$ to 1.6$)$ & $-0.04(-0.17$ to 0.09$)$ & 43 \\
\hline 851 & Concrete product makers, etc & $0.8(0.5$ to 1.5$)$ & $-0.05(-0.20$ to 0.11$)$ & 80 \\
\hline 201 & Accountants and book keepers & $0.8(0.5$ to 1.3$)$ & $-0.08(-0.28$ to 0.11$)$ & 119 \\
\hline 903 & Policemen and detectives & 0.8 (0.5 to 1.3$)$ & $-0.10(-0.29$ to 0.10$)$ & 126 \\
\hline 777 & $\begin{array}{l}\text { Wood working machine setters and } \\
\text { operators }\end{array}$ & $0.8(0.5$ to 1.2$)$ & $-0.13(-0.36$ to 0.09$)$ & 159 \\
\hline 332 & Shop managers & $0.8(0.6$ to 1.1$)$ & $-0.20(-0.49$ to 0.09$)$ & 236 \\
\hline 412 & Livestock workers (general) & $0.8(0.6$ to 1.1$)$ & $-0.23(-0.59$ to 0.13$)$ & 436 \\
\hline 411 & Farm helpers (general) & 0.8 (0.6 to 1.0$)$ & $-0.35(-0.76$ to 0.06$)$ & 429 \\
\hline 401 & $\begin{array}{l}\text { General farmers, livestock farmers } \\
\text { (working on own behalf) }\end{array}$ & $0.8(0.7$ to 1.0$)$ & $-2.20(-4.33$ to -0.42$)$ & 2763 \\
\hline 095 & Editors and journalists, etc & 0.7 (0.3 to 1.6$)$ & $-0.06(-0.17$ to 0.06$)$ & 44 \\
\hline 297 & $\begin{array}{l}\text { Real estate managers, store-room } \\
\text { keepers, etc }\end{array}$ & 0.7 (0.4 to 1.4$)$ & $-0.07(-0.21$ to 0.08$)$ & 64 \\
\hline 103 & $\begin{array}{l}\text { Leading administrators and executive } \\
\text { officials-local state administration }\end{array}$ & $0.7(0.3$ to 1.4$)$ & $-0.09(-0.22$ to 0.04$)$ & 57 \\
\hline 403 & $\begin{array}{l}\text { Gardeners, horticultural farmers and } \\
\text { fruit growers }\end{array}$ & $0.6(0.2$ to 1.5$)$ & $-0.08(-0.17$ to 0.02$)$ & 43 \\
\hline 021 & Veterinarians & $0.5(0.2$ to 1.5$)$ & $-0.08(-0.17$ to 0.02$)$ & 40 \\
\hline 432 & Fish hatchers & $0.5(0.2$ to 1.4$)$ & $-0.09(-0.19$ to 0.02$)$ & 61 \\
\hline 023 & $\begin{array}{l}\text { Agronomists and horticulturists, } \\
\text { agricultural consultants }\end{array}$ & $0.5(0.2$ to 1.1$)$ & $-0.15(-0.28$ to 0.00$)$ & 69 \\
\hline 292 & Clerks (bank) & $0.4(0.2$ to 1.2$)$ & $-0.13(-0.23$ to 0.00$)$ & 67 \\
\hline 699 & $\begin{array}{l}\text { Others in } 69 \text { other transport and } \\
\text { communication work }\end{array}$ & $0.3(0.1$ to 1.0$)$ & $-0.15(-0.22$ to 0.00$)$ & 40 \\
\hline
\end{tabular}


Table 5 Predicted age-adjusted PR and AFs of tinnitus among women*

\begin{tabular}{|c|c|c|c|c|}
\hline \multicolumn{2}{|c|}{ Nordic Classification of Occupational Codes } & \multirow{2}{*}{$\frac{\text { PR }(95 \% \mathbf{C l})}{1.9(1.1 \text { to } 3.3)}$} & \multirow{2}{*}{$\frac{\mathrm{AF}(\%) \dagger(95 \% \mathrm{Cl})}{0.18(0.01 \text { to } 0.41)}$} & \multirow{2}{*}{$\begin{array}{l}\begin{array}{l}\text { Sample } \\
\text { size }(26574)\end{array} \\
73\end{array}$} \\
\hline 013 & Laboratory assistants & & & \\
\hline 294 & Clerks (public health insurance) & $1.6(0.9$ to 3.0$)$ & $0.12(-0.05$ to 0.32$)$ & 68 \\
\hline 681 & Postmen & $1.6(0.8$ to 3.4$)$ & $0.07(-0.05$ to 0.23$)$ & 41 \\
\hline $\mathrm{X}$ & Occupation not reported & 1.5 (1.3 to 1.8$)$ & 11.30 (6.96 to 15.62$)$ & 7946 \\
\hline 915 & Housekeepers (public service) & 1.5 (1.2 to 1.8$)$ & $1.42(0.59$ to 2.30$)$ & 842 \\
\hline 049 & Others in 04 nursing care & $1.5(1.1$ to 2.0$)$ & $0.52(0.11$ to 0.96$)$ & 355 \\
\hline 921 & Headwaiters, waiters & $1.5(1.1$ to 2.1$)$ & $0.43(0.05$ to 0.83$)$ & 295 \\
\hline 914 & Housekeepers, maids (private service) & 1.5 (1.0 to 2.2$)$ & $0.29(-0.01$ to 0.63$)$ & 212 \\
\hline 911 & $\begin{array}{l}\text { Housekeepers, etc (not private or } \\
\text { public service) }\end{array}$ & 1.5 (1.0 to 2.2$)$ & $0.20(-0.07$ to 0.50$)$ & 129 \\
\hline 861 & Packers, labellers and related workers & 1.5 (0.9 to 2.4$)$ & $0.18(-0.06$ to 0.44$)$ & 111 \\
\hline 853 & Plastic product makers & 1.4 (0.8 to 2.4$)$ & $0.11(-0.09$ to 0.35$)$ & 102 \\
\hline $0 \times 3$ & $\begin{array}{l}\text { Librarians, archivists and scientific } \\
\text { personnel in museums }\end{array}$ & $1.4(0.7$ to 2.8$)$ & $0.06(-0.08$ to 0.23$)$ & 47 \\
\hline 003 & $\begin{array}{l}\text { Other engineers, engineer technicians, } \\
\text { industrial designers, draughtsman }\end{array}$ & $1.4(0.6$ to 3.3$)$ & $0.04(-0.07$ to 0.18$)$ & 48 \\
\hline 932 & Char workers and cleaners & $1.3(1.1$ to 1.6$)$ & $2.03(0.64$ to 3.43$)$ & 1888 \\
\hline 913 & Kitchen assistants & $1.3(0.9$ to 1.7$)$ & $0.32(-0.15$ to 0.80$)$ & 404 \\
\hline 716 & $\begin{array}{l}\text { Sewers and embroiderers (textile products, } \\
\text { leather garments) }\end{array}$ & $1.3(0.7$ to 2.2$)$ & $0.09(-0.11$ to 0.29$)$ & 94 \\
\hline 825 & Canning and other preservation workers & $1.3(0.7$ to 2.5$)$ & $0.06(-0.09$ to 0.25$)$ & 80 \\
\hline 104 & $\begin{array}{l}\text { Other administration governmental } \\
\text { servants-local state administration }\end{array}$ & $1.3(0.7$ to 2.6$)$ & $0.06(-0.09$ to 0.23$)$ & 58 \\
\hline 822 & Bakers and pastry cooks & $1.3(0.6$ to 2.6$)$ & $0.04(-0.10$ to 0.18$)$ & 45 \\
\hline$Y \ddagger$ & Occupations with $<40$ subjects & $1.2(1.0$ to 1.5$)$ & $0.82(-0.15$ to 1.87$)$ & 1449 \\
\hline 045 & Other practical nurses & $1.2(0.9$ to 1.5$)$ & $0.60(-0.15$ to 1.35$)$ & 1063 \\
\hline 411 & Farm helpers (general) & $1.2(0.9$ to 1.5$)$ & $0.53(-0.23$ to 1.29$)$ & 843 \\
\hline 912 & Cooks & $1.2(0.9$ to 1.8$)$ & $0.20(-0.15$ to 0.57$)$ & 247 \\
\hline 919 & $\begin{array}{l}\text { Others in } 91 \text { public safety and protection } \\
\text { work }\end{array}$ & $1.2(0.8$ to 1.8$)$ & $0.17(-0.17$ to 0.53$)$ & 310 \\
\hline 671 & Local postmasters, postal assistance & $1.2(0.8$ to 1.9$)$ & $0.12(-0.17$ to 0.40$)$ & 203 \\
\hline 941 & Barbers, hairdressers and beauticians & $1.2(0.8$ to 1.9$)$ & $0.10(-0.16$ to 0.37$)$ & 186 \\
\hline 292 & Clerks (bank) & $1.2(0.7$ to 1.9$)$ & $0.09(-0.15$ to 0.37$)$ & 202 \\
\hline 413 & Nursery workers and gardeners & $1.2(0.7$ to 2.1$)$ & $0.08(-0.14$ to 0.30$)$ & 106 \\
\hline 046 & Dental assistance & 1.2 (0.7 to 2.2$)$ & $0.07(-0.10$ to 0.26$)$ & 93 \\
\hline 675 & Telegraph dispatchers & $1.2(0.6$ to 2.4$)$ & $0.05(-0.10$ to 0.22$)$ & 62 \\
\hline 059 & $\begin{array}{l}\text { Others in } 05 \text { other professional health } \\
\text { and medical work }\end{array}$ & $1.2(0.5$ to 2.7$)$ & $0.02(-0.09$ to 0.17$)$ & 53 \\
\hline 333 & Shop assistants & $1.1(0.9$ to 1.4$)$ & $0.59(-0.73$ to 1.91$)$ & 2042 \\
\hline 401 & $\begin{array}{l}\text { General farmers, livestock farmers } \\
\text { (working on own behalf) }\end{array}$ & $1.1(0.8$ to 1.4$)$ & $0.24(-0.47$ to 1.05$)$ & 905 \\
\hline 04 & Nursing care & $1.1(0.7$ to 1.8$)$ & $0.04(-0.18$ to 0.30$)$ & 120 \\
\hline 211 & Secretaries and stenographers & $1.1(0.6$ to 1.8$)$ & $0.02(-0.20$ to 0.29$)$ & 161 \\
\hline 302 & Working proprietors, retail trade & $1.1(0.6$ to 1.9$)$ & $0.02(-0.16$ to 0.23$)$ & 94 \\
\hline 043 & Practical nurses in psychiatric institutions & $1.1(0.5$ to 2.4$)$ & $0.02(-0.12$ to 0.18$)$ & 67 \\
\hline 111 & Directors, managers, and working proprietors & 1.1 (0.5 to 2.6$)$ & $0.02(-0.10$ to 0.14$)$ & 42 \\
\hline 412 & Livestock workers (general) & 1.0 (0.8 to 1.4$)$ & $0.05(-0.51$ to 0.60$)$ & 439 \\
\hline 299 & Others in 29 other clerical work & 1.0 (0.8 to 1.3$)$ & $0.03(-1.05$ to 1.11$)$ & 1636 \\
\hline 673 & $\begin{array}{l}\text { Telephone switchboard operators } \\
\text { (public service) }\end{array}$ & $1.0(0.5$ to 2.2$)$ & $0.01(-0.12$ to 0.16$)$ & 47 \\
\hline 951 & Laundry and dry-cleaning workers & $1.0(0.5$ to 1.9$)$ & $0.00(-0.17$ to 0.19$)$ & 81 \\
\hline 06 & Pedagogical work & 1.0 (ref) & 0.00 (ref) & 1299 \\
\hline $0 \times 2$ & Social workers & $1.0(0.6$ to 1.5$)$ & $-0.01(-0.29$ to 0.29$)$ & 263 \\
\hline 922 & Other waiting personnel & 1.0 (0.6 to 1.7$)$ & $-0.01(-0.22$ to 0.21$)$ & 136 \\
\hline 201 & Accountants and book-keepers & 0.9 (0.5 to 1.8$)$ & $-0.02(-0.20$ to 0.19$)$ & 121 \\
\hline 674 & $\begin{array}{l}\text { Telephone switchboard operators } \\
\text { (private exchange) }\end{array}$ & 0.9 (0.3 to 2.3$)$ & $-0.02(-0.11$ to 0.11$)$ & 48 \\
\hline 41 & Farm work and livestock work & 0.9 (0.4 to 2.0$)$ & $-0.02(-0.16$ to 0.14$)$ & 56 \\
\hline
\end{tabular}


Table 5 Continued

\begin{tabular}{|c|c|c|c|c|}
\hline \multicolumn{2}{|c|}{ Nordic Classification of Occupational Codes } & \multirow{2}{*}{$\frac{\text { PR }(95 \% \text { Cl) }}{0.9(0.4 \text { to } 1.7)}$} & \multirow{2}{*}{$\frac{\text { AF }(\%) \dagger(95 \% \text { Cl })}{-0.04(-0.19 \text { to } 0.14)}$} & \multirow{2}{*}{$\begin{array}{l}\begin{array}{l}\text { Sample } \\
\text { size }(26574)\end{array} \\
89\end{array}$} \\
\hline 332 & Shop managers & & & \\
\hline 041 & Professional nurses & $0.9(0.7$ to 1.3$)$ & $-0.13(-0.69$ to 0.46$)$ & 745 \\
\hline 052 & Physio- and occupational therapists & $0.8(0.4$ to 1.5$)$ & $-0.07(-0.26$ to 0.15$)$ & 134 \\
\hline 203 & Other cashiers & $0.8(0.5$ to 1.4$)$ & $-0.09(-0.31$ to 0.15$)$ & 176 \\
\hline 916 & Concierge (hotels) & $0.7(0.2$ to 2.0$)$ & $-0.05(-0.13$ to 0.07$)$ & 51 \\
\hline 047 & $\begin{array}{l}\text { Nursemaids in hospitals and other } \\
\text { institutions }\end{array}$ & $0.3(0.1$ to 1.0$)$ & $-0.20(-0.31$ to 0.00$)$ & 119 \\
\hline 769 & Others in 76 electrical work & $0.2(0.0$ to 1.6$)$ & $-0.10(-0.14$ to 0.00$)$ & 48 \\
\hline
\end{tabular}

in regard to the effects of occupation on hearing loss based on this same study sample. ${ }^{19}$

In women, occupations with the highest risk for tinnitus were not typically noisy ones, and the AF was determined mainly by the group of occupationally inactive. This is different from the analysis of occupation effects on hearing loss ${ }^{19}$ - there was no increased risk of hearing loss in occupationally inactive women.

Only a few previous studies have reported occupationspecific tinnitus prevalence. The odds for tinnitus according to different occupational groups were reported based on the 1994-1995 US National Health Interview Survey Disability Supplement data set. ${ }^{4}$ This study showed a marginal elevation in tinnitus prevalence in skilled and unskilled workers compared with professionals (OR 1.18; 95\% CI 1.00 to 1.39 ). This study also found a reduced prevalence in the two occupational groups of managerial or administrative (OR 0.82; $95 \%$ CI 0.68 to 0.99 ) and technical or sales (OR $0.83 ; 95 \%$ CI 0.70 to 0.98$)$.

Some studies evaluating the effect of self-reported occupational noise exposure found results comparable to the present study. In a British general population sample of 12907 subjects, ${ }^{9}$ age-adjusted PRs for working in noisy environment for $>10$ years was estimated to be $2.6(95 \%$ CI 2.0 to 3.4$)$ in men and 1.9 (95\% CI 1.0 to $3.7)$ in women in comparison with those with no occupational exposure to noise. The overall tinnitus prevalence of the sample was $6 \%$ in men and $3 \%$ in women. Previous British data also showed tinnitus to be about twice as common in those with a history of occupational exposure to noise. ${ }^{28}$

In an earlier analysis of tinnitus in the NTHLS, being exposed to loud noise at work for $>15$ hours per week resulted in an OR of 1.7 (95\% CI 1.5 to 1.9$)$ in men and $1.6(95 \%$ CI 1.4 to 1.9$)$ in women compared with those who had not been exposed to loud noise at work. ${ }^{4}$

Among 2015 older Australians, the RR of tinnitus was $1.4(95 \%$ CI 1.1 to 1.7$)$ for participants exposed to 'tolerable noise' and 1.5 (95\% CI 1.11 to 2.1) for those exposed to high levels of occupational noise ("unable to hear speech') compared with unexposed participants. Among 3753 older adults in Beaver Dam, Wisconsin, no association was found between major occupation, history of occupational noise exposure or hunting history, with the likelihood of having tinnitus (prevalence) or developing tinnitus (incidence). ${ }^{5}$

We found adding hearing loss as a predictor did not decrease the effect of occupation; when controlling for some other risk factors, a small increase in occupational effect was found. Thus, hearing loss does not seem to mediate, but rather suppress, the effect of occupation on tinnitus. This points to the importance of occupational risk factors not related to hearing loss, such as work demands, level of control, social support and other psychosocial factors.

The negative effect for women of being occupationally non-active is partly in agreement with results from a study of self-reported hearing problems in a Swedish working and non-working population. ${ }^{11} \mathrm{~A}$ higher prevalence of frequent or constant tinnitus was found among non-workers $(15 \%)$ than workers $(11 \%)$. While we found this effect mainly among women, the previous study reported higher effects for men $(25 \%$ and $15 \%$ for nonworkers and workers, respectively) than for women $(10 \%$ and $8 \%$ ). These numbers were not age-adjusted, however, and the age distribution of workers was quite different from non-workers.

Receiving social security or disability pension was associated with the highest risk of tinnitus in the group of occupationally non-active women. It may be that reduced functional ability or poor general health decreases the ability to cope with tinnitus, although the causal direction is not clear, as tinnitus may well be a part of the disability in the first place. Also, the increased risk of tinnitus may be related to psychosocial factors, such as loss of social status and self-esteem, social support, personal economy and lifestyle factors such as physical inactivity. Regardless of the underlying cause, the elevated occurrence of tinnitus among unemployed women is hardly a real occupational effect, so the true fraction of tinnitus attributable to type of occupation is 
much lower than the $21.4 \%$ estimated by including unemployed women.

\section{Strengths and limitations}

The major advantages of the present study are the prospective design and that the study population is representative of the general working population. A substantial selection bias is unlikely since occupational data were complete for all participants, and the participation rate in this population survey was relatively high (69\% for the vast majority of the county).

A recent survey of sufferers from tinnitus showed that they report excessive noise in the work environment as the single most important factor for developing tinnitus. ${ }^{29}$ Thus, there might be a serious problem with recall bias that tends to exaggerate an association when both the exposure and the outcome are self-reported. In the present study, occupation data were obtained from highly valid prospective registry data, thus, we consider recall bias on this factor not to be a problem.

Test-retest of the question 'are you bothered by tinnitus?' indicated a relatively high reliability. Tinnitus is a personal, subjective experience that cannot be measured objectively and is thus per definition described by self report. The clinical validity of the measure is unknown as we have no data on the correlation between being bothered by tinnitus and seeking medical help. Subjective need for treatment has been reported in as many as $2 / 3$ of the subjects who found them self-suffering from tinnitus often or always. ${ }^{30}$ The prevalence of suffering from tinnitus in that study was reported to be $14 \%$, which is very similar to the prevalence of bothered by tinnitus in our study. But probably only a few per cent of the subjects with bothersome tinnitus have actually been seeking help for this condition, a number that will depend on factors such as whether treatments are determined to be effective and if they are known or available to the broader public.

A weakness of the study is the lack of information about the duration of employment and exposure. However, the estimated average tinnitus prevalence for each occupation group applies to workers whose age is equal to the sample mean. Accordingly, we have essentially adjusted for exposure duration.

The Nordic Classification of Occupations does not classify occupations on the basis of noise exposure levels or other risk factors for tinnitus, but according to the tasks and duties undertaken in the job. Heterogeneity regarding noise and other exposure within occupational categories implies that occupation, as an explanatory variable, does not capture all effects of occupational exposures on tinnitus. Our results showed that adding information on self-reported occupational noise exposure improved the prediction of tinnitus somewhat.

Selection for good hearing function in some occupations could in principle bias the results, but we think it unlikely that this type of selection had a major effect on our results.

\section{CONCLUSIONS}

This study found a moderate association between occupation and tinnitus. Estimates of occupation-specific tinnitus prevalence may help identify high-risk occupations in which interventions are needed.

Acknowledgements The Nord-Trøndelag Health Study (The HUNT Study) is a collaboration between the HUNT Research Centre (Faculty of Medicine, the Norwegian University of Science and Technology), the Nord-Trøndelag County Council and the Norwegian Institute of Public Health.

Funding This work was supported by the National Institute on Deafness and Other Communication Disorders (NIDCD), National Institutes of Health (NIH) via research contract No. N01-DC-6-2104.

Competing interests None.

Patient consent Obtained.

Ethics approval The study was approved by the Norwegian Regional Committee of Medical Ethics and by the Norwegian Data Inspectorate.

Contributors The following authors have contributed to the paper: BE: Design, analysis and interpretation of data, writing. NHK: Preparing data, drafting the manuscript, critical revision of manuscript. EK: Preparing data, drafting the manuscript, critical revision of manuscript. HJH: Obtaining funding, data acquisition, drafting the manuscript, critical revision of manuscript. KT: Conception and design, obtaining funding, data acquisition, drafting the manuscript, critical revision of manuscript.

Provenance and peer review Not commissioned; externally peer reviewed.

Data sharing statements There is no additional data available.

\section{REFERENCES}

1. Erlandsson SI. Psychological profiles of tinnitus patients. In: Tyler RS, ed. Tinnitus Handbook. San Diego: Thomson Learning 2000:25-57.

2. Henry JA, Dennis KC, Schechter MA. General review of tinnitus: prevalence, mechanisms, effects, and management. J Speech Lang Hear Res 2005;48:1204-35.

3. Shargorodsky J, Curhan GC, Farwell WR. Prevalence and characteristics of tinnitus among US adults. Am J Med 2010;123:711-18.

4. Hoffman HJ, Reed GW. Epidemiology of tinnitus. In: Snow Jr JB, ed. Tinnitus: Theory and Management. Hamilton Ontario: BC Decker Inc, 2004:16-41.

5. Nondahl DM, Cruickshanks KJ, Wiley TL, et al. Prevalence and 5-year incidence of tinnitus among older adults: the epidemiology of hearing loss study. J Am Acad Audiol 2002;13:323-31.

6. Konig O, Schaette R, Kempter R, et al. Course of hearing loss and occurrence of tinnitus. Hear Res 2006;221:59-64.

7. Sindhusake D, Golding M, Newall $P$, et al. Risk factors for tinnitus in a population of older adults: the Blue Mountains Hearing Study. Ear Hear 2003;24:501-7.

8. Sulkowski W, Kowalska S, Lipowczan A, et al. Tinnitus and impulse noise-induced hearing loss in drop-forge operators. Int J Occup Med Environ Health 1999;12:177-82.

9. Palmer KT, Griffin MJ, Syddall HE, et al. Occupational exposure to noise and the attributable burden of hearing difficulties in Great Britain. Occup Environ Med 2002;59:634-9.

10. Gopinath B, McMahon CM, Rochtchina E, et al. Risk factors and impacts of incident tinnitus in older adults. Ann Epidemiol 2010;20:129-35.

11. Hasson D, Theorell $\mathrm{T}$, Westerlund $\mathrm{H}$, et al. Prevalence and characteristics of hearing problems in a working and non-working Swedish population. J Epidemiol Community Health 2010;64:453-60.

12. Griest SE, Bishop PM. Tinnitus as an early indicator of permanent hearing loss. A 15 year longitudinal study of noise exposed workers. AAOHN J 1998;46:325-9.

13. Rubak T, Kock S, Koefoed-Nielsen B, et al. The risk of tinnitus following occupational noise exposure in workers with hearing loss or normal hearing. Int J Audiol 2008;47:109-14.

14. Saunders JC. The role of central nervous system plasticity in tinnitus. J Commun Disord 2007;40:313-34.

15. Lin YH, Chen CY, Lu SY. Physical discomfort and psychosocial job stress among male and female operators at telecommunication call centers in Taiwan. Appl Ergon 2009;40:561-8. 
16. Hinton DE, Chhean D, Pich V, et al. Tinnitus among Cambodian refugees: relationship to PTSD severity. $J$ Trauma Stress 2006; 19:541-6.

17. Krog NH, Engdahl B, Tambs K. The association between tinnitus and mental health in a general population sample: results from the HUNT Study. J Psychosom Res 2010;69:289-98.

18. Guitton MJ. Tinnitus and anxiety: more than meets the ear. Curr Psychiatry Rev 2006;2:333-8.

19. Engdahl B, Tambs K. Occupation and the risk of hearing impairment-results from the Nord-Trøndelag study on hearing loss. Scand J Work Environ Health 2010;36:250-7.

20. Tambs K, Hoffman HJ, Borchgrevink HM, et al. Hearing loss induced by noise, ear infections, and head injuries: results from the Nord-Trøndelag Hearing Loss Study. Int J Audiol 2003;42:89-105.

21. Kvestad E, Czajkowski N, Engdahl B, et al. Low heritability of tinnitus: results from the second Nord-Trondelag health study. Arch Otolaryngol Head Neck Surg 2010;136:178-82.

22. Statistics Norway. Nordic Classification of Occupations. Oslo: Statistics Norway, 1976

23. Vassenden K. Censuses 1960, 1970 and 1980. Documentation of the Comparable Files. 87/2. Oslo, Norway: Statistics Norway, 1987.
24. Engdahl B, Tambs K, Borchgrevink HM, et al. Screened and unscreened hearing threshold levels for the adult population: results from the Nord-Trøndelag Hearing Loss Study. Int J Audiol 2005:44:213-30.

25. Barros AJ, Hirakata VN. Alternatives for logistic regression in crosssectional studies: an empirical comparison of models that directly estimate the prevalence ratio. BMC Med Res Methodol 2003;3:21

26. McFadden D. Quantitative methods for analyzing travel behaviour of individuals: some recent developments. In: Hensher D, Stopher P, eds. Behavioural Travel Modelling. London: Croom Helm London, 1978:279-318.

27. Miettinen OS. Proportion of disease caused or prevented by a given exposure, trait or intervention. Am J Epidemiol 1974;99:325-32.

28. Coles RR. Epidemiology of tinnitus: (1) prevalence. J Laryngol Otol Suppl 1984:9:7-15.

29. Sufferers blame occupational noise for their tinnitus. Deafness Research UK Web site. 2010. http://www.deafnessresearch.org.uk/ Sufferers\%20blame\%20occupational\%20noise\%20for\%20their\% 20tinnitus+4318.twl (accessed 1 Jul 2011).

30. Axelsson A, Ringdahl A. Tinnitus - a study of its prevalence and characteristics. Br J Audiol 1989;23:53-62. 